\title{
Antithrombotic therapy in patients with cerebral microbleeds
}

D Wilson, DJ Werring

${ }^{1}$ Stroke Research Centre, Department of brain repair and rehabilitation, UCL Institute of Neurology, First Floor, Russell Square House, London

The National Hospital for Neurology and Neurosurgery, Queen Square, London WC1N 3BG, UK

*Corresponding author: Dr. David J Werring, Professor of Clinical Neurology, Stroke Research Centre, UCL Institute of Neurology, and National Hospital for Neurology and Neurosurgery, Box 6, Queen Square, London WC1N 3BG, United-Kingdom; email address: d.werring@ucl.ac.uk ; telephone number: +44 (0)20 34483541

Abstract: 200 words

Body text (excluding references): 2491 words 


\section{Abstract (<200 words)}

Purpose of review: Cerebral microbleeds (CMBs) are a radiological marker of cerebral small vessel disease corresponding to small haemosiderin foci identified by blood-sensitive MRI. CMBs are common in older community populations, and in individuals with ischaemic stroke (IS) or TIA, and intracerebral haemorrhage (ICH). We summarize how CMBs might contribute to assessing the future risk of IS and ICH to inform antithrombotic (antiplatelet or anticoagulant) decisions.

Recent findings: CMBs are a risk factor for future IS and ICH in all community and hospital populations studied. Following IS/TIA treated with antithrombotics, increasing CMB burden increases the risk of ICH more steeply than that of IS. In ICH populations the risk of recurrent $\mathrm{ICH}$ increases with $\mathrm{CMB}$ burden, and is highest in those with strictly lobar CMBs or other haemorrhagic findings (e.g. cortical superficial siderosis) suggesting cerebral amyloid angiopathy (CAA).

Summary: In IS or TIA patients <5 CMBs should not affect antithrombotic decisions, though with $>5 \mathrm{CMBs}$ the risks of future ICH and IS are finely balanced, and antithrombotics might cause net harm. In lobar ICH populations, a high burden of strictly lobar CMBs is associated with CAA and high ICH risk; antithrombotics should be avoided unless there is a compelling indication.

\section{Key words}

Cerebral microbleeds, antithormbotics, anticoagulants, antiplatelets, ischaemic stroke, intracerebral haemorrhage

(200 words) 


\section{Introduction}

Although cerebral microbleeds (CMBs) have been extensively investigated since their first description in 1996 (1), important questions about underlying mechanisms and clinical relevance remain unanswered. CMBs are the radiological correlate of haemosiderin-laden macrophages resulting from small, usually chronic haemorrhages (2-4). Interest has focussed on CMBs as a potential marker of a "bleeding prone" small vessel arteriopathies, with potential to predict symptomatic intracerebral haemorrhage (ICH) risk $(5,6)$. However, CMBs are also a risk factor for ischaemic stroke $(7,8)$, possibly explained by alternative "ischaemic" pathophysiological mechanisms(9-11). Antithrombotic (antiplatelet and anticoagulant) use in patients with CMBs is a highly topical clinical dilemma (12), which will become increasingly common with an aging population often investigated with MRI and exposed to antithrombotic drugs for stroke and cardiovascular prevention. This review provides up-to-date information on the clinical relevance of CMBs for antithrombotic use.

\section{Definition, mechanisms and potential relevance of CMBs for antithrombotic decisions}

CMBs are defined radiologically as small (generally $<10 \mathrm{~mm}$ ) ovoid or rounded black signal voids on paramagnetic-sensitive MRI sequences, including $\mathrm{T} 2 *$ gradient-recalled echo weighted and susceptibility-weighted imaging(13). CMBs must be differentiated from "mimics" (13), and account taken of technical imaging aspects affecting detection (14-16). Standardised rating scales or automated techniques can improve reliability of CMB rating (17-19). Studies of the pathological correlates of CMBs include only 23 patients $(4,20)$ mainly with ICH or dementia. Nevertheless, most observations suggest that CMBs are selflimiting regions of red cell extravasation from damaged small blood vessels. CMB location predicts the type of underlying small vessel disease: an arteriopathy associated with systemic 
arterial hypertension and pathological changes in small perforating arteries of the deep grey and white matter (often termed "hypertensive arteriopathy') causes CMBs in deep (basal ganglia) as well as lobar regions. In Western (Caucasian) people with $\mathrm{ICH}, \mathrm{CMBs}$ in a strictly lobar distribution are highly specific for cerebral amyloid angiopathy (CAA), which causes progressive deposition of amyloid- $\beta$ in small cortical and leptomeningeal arterial walls(3), though this pattern might not be so specific in Eastern (Asian) people and in those without $\operatorname{ICH}(21,22)$. Figure 1 shows the different radiological distributions of CMBs.

More recently, ischaemic mechanisms for CMBs have been identified: ischaemia-mediated iron store released by oligodendrocytes; (9) phagocytosis of red cell microemboli into the perivascular space (termed angiophagy); (10) and haemorrhagic transformation of microinfarcts (11), which might contribute to the clinical associations between CMBs and future IS risk.

CMBs might be relevant for ICH risk with antithrombotic exposure: first, CMBs are common in populations likely to be exposed to antithrombotic drugs, including older communitydwelling individuals and those with IS, TIA or ICH (23); and second, longitudinal studies confirm that CMBs are a dynamically develop over time after IS, TIA or ICH $(24,25)$ (while regression of CMBs can occur, it seems to be rare). Since antithrombotics impair haemostasis by inhibiting platelet aggregation (antiplatelets) or disrupting the coagulation pathway (anticoagulants), in the presence of a CMB-related arteriopathy, normally self-limiting red blood cell extravasation (causing a CMB) could become a symptomatic ICH (Figure 2). 


\section{Current evidence on clinical outcomes following antithrombotic use in different populations evaluated for CMBs}

When CMBs are detected in a patient with a risk of future ischaemic vaso-occlusive disease, should antithrombotic drugs be recommended? Without randomised trial data, the best evidence is from prospective observational cohorts and pooled meta-analyses. We suggest considering: the population (non-stroke, IS/TIA, or ICH); the type of antithrombotic (antiplatelet or anticoagulant); the overall risk of IS and ICH; CMB presence, burden and distribution; the balance of future IS and $\mathrm{ICH}$; and judgement of the likely net benefit and harm of antithrombotic treatment (Table 1). 
Table 1. Summary of evidence on IS and ICH risk by CMB presence, burden and distribution 


\begin{tabular}{|c|c|c|c|}
\hline & $\begin{array}{l}\text { Non-stroke (older } \\
\text { community) }\end{array}$ & $\begin{array}{l}\text { Ischaemic stroke and } \\
\text { TIA }\end{array}$ & $\begin{array}{l}\text { Intracerebral } \\
\text { haemorrhage }\end{array}$ \\
\hline $\begin{array}{l}\text { Effect of } \mathbf{C M B} \\
\text { presence } \\
\text { (compared to no } \\
\text { CMBs) }\end{array}$ & 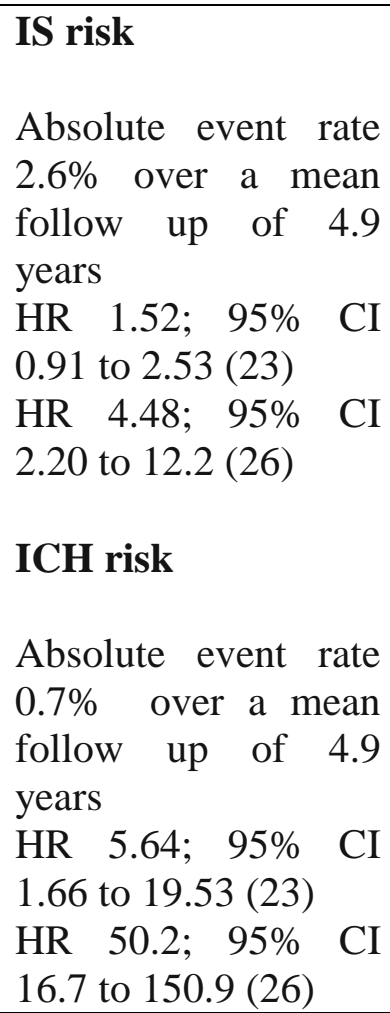 & $\begin{array}{l}\text { IS risk } \\
\text { Absolute event rate } \\
9 \% \text { over a median } \\
\text { follow up of } 18 \\
\text { months } \\
\text { Absolute risk increase } \\
3.4 \% \text {. } \\
\text { Pooled risk ratio } 1.8 \\
(27) \\
\text { ICH risk } \\
\text { Absolute event rate } \\
\text { over a median follow } \\
\text { up of } 18 \text { months } 4.3 \% \\
\text { Absolute risk increase } \\
3.8 \% \text {. } \\
\text { Pooled risk ratio } 6.3 \\
\text { (27) }\end{array}$ & $\begin{array}{l}\text { ICH risk } \\
\text { Baseline CMBs } \\
\text { associated with } \\
\text { recurrent } \mathrm{ICH} \text { in lobar } \\
\text { but not deep ICH (28) }\end{array}$ \\
\hline $\begin{array}{l}\text { Effect of CMB } \\
\text { burden } \\
\text { (all data compared } \\
\text { to those without } \\
\text { CMBs) }\end{array}$ & $\begin{array}{l}\text { All stroke risk } \\
\text { Increased risk of 'all } \\
\text { stroke' with } 2-4 \\
\text { CMBs and }>5 \text { CMBs } \\
(23)\end{array}$ & 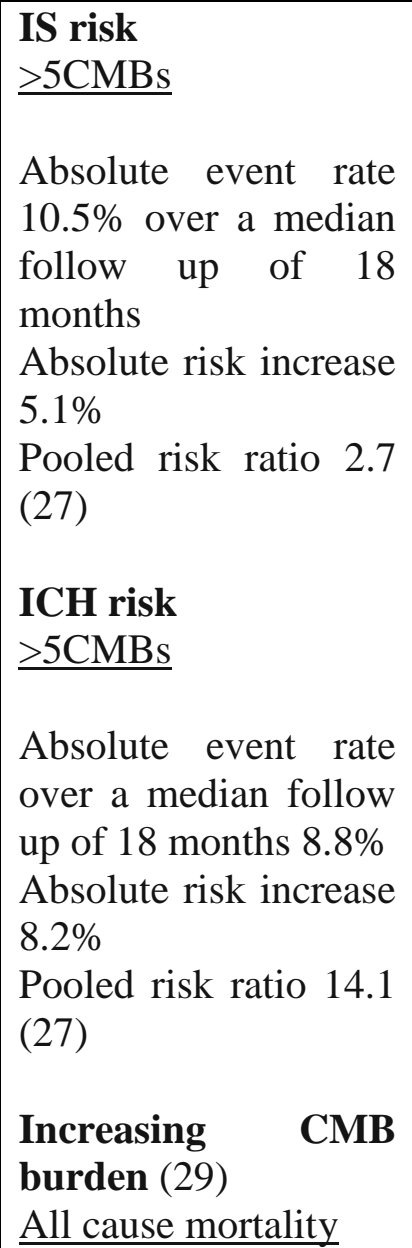 & $\begin{array}{l}\text { ICH risk } \\
\text { Baseline number of } \\
\text { CMBs associated with } \\
\text { recurrent ICH in lobar } \\
\text { but not deep ICH (28) } \\
>5 \text { CMBs } \\
\text { HR } 4.12 \text { 95\% CI } 1.6 \\
\text { to } 9.3 \text { in patients with } \\
\text { CAA-related ICH (30) } \\
3 \text { year cumulative risk } \\
51 \% \text { in those with } \\
\text { lobar ICH (5) }\end{array}$ \\
\hline
\end{tabular}




\begin{tabular}{|c|c|c|c|}
\hline & & $\begin{array}{l}\text { HR } 1.99 ; 95 \% \text { CI } 1.03 \\
\text { to } 3.85 \\
\text { IS mortality } \\
\text { HR } 3.39 ; 95 \% \text { CI } 1.39 \\
\text { to } 8.28 .\end{array}$ & \\
\hline $\begin{array}{l}\text { Effect of CMB } \\
\text { distribution } \\
\text { (compared to no } \\
\text { CMBs) }\end{array}$ & 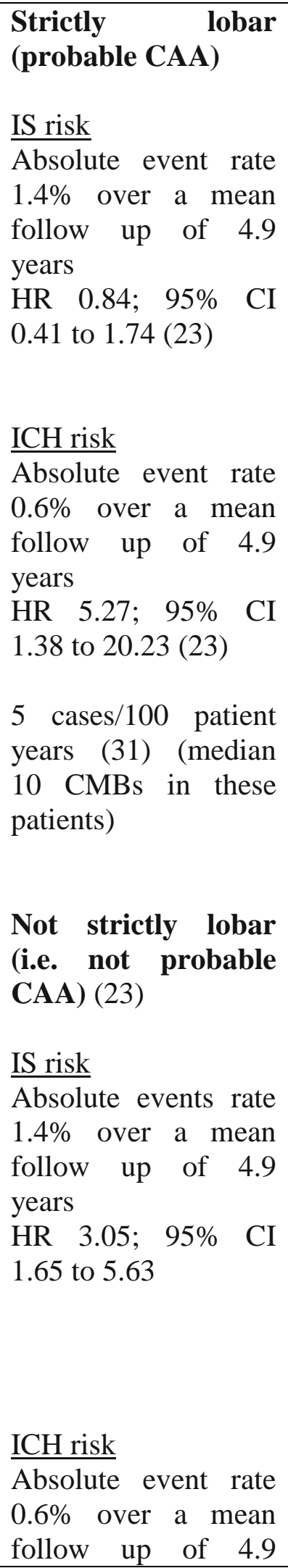 & $\begin{array}{l}\text { Strictly lobar } \\
\text { (probable CAA) } \\
\text { IS risk } \\
\text { Absolute event rate } \\
\text { over a median follow } \\
\text { up of } 18 \text { months 9.3\% } \\
\text { Absolute risk increase } \\
3.9 \% \text {. } \\
\text { Pooled risk ratio } 2.0 \\
\text { (27) } \\
\text { ICH risk } \\
\text { Absolute event rate } \\
\text { over a median follow } \\
\text { up of } 18 \text { months } 3.6 \% \\
\text { Absolute risk increase } \\
3.2 \% \\
\text { Pooled risk ratio } 10.5 \\
(27) \\
\text { ICH risk } \\
\text { Absolute event rate } \\
\text { over a median follow } \\
\text { up of } 18 \text { months } 6.1 \% \\
\text { ICH mortality } \\
\text { HR 5.91; 95\% CI } 1.58 \\
\text { to } 22.11(29) \\
\text { Mixed CMBs } \\
\text { IS risk } \\
\text { Absolute event rate } \\
\text { over a median follow } \\
\text { up of } 18 \text { months } \\
10.7 \% \\
\text { Absolute risk increase } \\
5.3 \% \\
\text { Pooled risk ratio } 2.6 \\
(27)\end{array}$ & $\begin{array}{l}\text { Probable } \\
\text { patients } \\
\text { ICH risk } \\
3 \text { year cumulative ICH } \\
\text { rates (5) 17\% 2 } \\
\text { strictly lobar CMBs, } \\
37 \% \text { 3-5 strictly lobar } \\
\text { CMBs, } \\
51 \% \quad \text { strictly lobar } \\
\text { CMBs } \\
8.9 \text { events/ 100 patient } \\
\text { years (31) } \\
\text { 2-4 CMBs (30) } \\
\text { HR 2.9; 95\% CI 1.3 to } \\
4.0 ; \\
\frac{>5 \text { CMBs (30) }}{\text { HR 4.12; 95\% CI 1.6- }} \\
9.3\end{array}$ \\
\hline
\end{tabular}




\begin{tabular}{|c|c|c|c|}
\hline & $\begin{array}{l}\text { years } \\
\mathrm{HR} 5.27 ; 95 \% \quad \mathrm{CI} \\
1.07 \text { to } 32.86\end{array}$ & $\begin{array}{l}\text { Absolute risk increase } \\
5.7 \% \\
\text { Pooled risk ratio } 11.1 \\
(27)\end{array}$ & \\
\hline $\begin{array}{l}\text { Antithrombotic- } \\
\text { CMB interactions }\end{array}$ & $\begin{array}{l}\text { Antiplatelets did not } \\
\text { significantly change } \\
\text { IS or ICH risk } \\
\text { according to CMB } \\
\text { presence, burden or } \\
\text { distribution(23) }\end{array}$ & $\begin{array}{l}\text { Risks outlined above } \\
\text { (excluding } \\
\text { mortality) are for } \\
\text { patients largely on } \\
\text { antiplatelets. No data } \\
\text { on interaction } \\
\text { available. } \\
\text { ICH mortality was } \\
\text { from patients on } \\
\text { anticoagulants. }\end{array}$ & $\begin{array}{l}\text { ICH risk in CAA } \\
\frac{\text { Aspirin }}{\text { HR } 3.95 ; 95 \% \text { CI } 1.6} \\
\text { to } 8.3(30)\end{array}$ \\
\hline $\begin{array}{l}\text { Conclusions and } \\
\text { recommendations }\end{array}$ & $\begin{array}{l}\text { CMBs increase the } \\
\text { risk of both ICH and } \\
\text { IS. Those in a strictly } \\
\text { lobar distribution } \\
\text { have a higher risk of } \\
\text { ICH. } \\
\text { However, currently } \\
\text { neither presence, } \\
\text { burden or } \\
\text { distribution should } \\
\text { routinely affect } \\
\text { antithrombotic } \\
\text { decisions }\end{array}$ & $\begin{array}{l}\text { CMBs increase the } \\
\text { risk of both IS and } \\
\text { ICH. An increasing } \\
\text { burden increased the } \\
\text { risk of ICH more } \\
\text { dramatically than the } \\
\text { risk of IS, but } \\
\text { absolute rates of IS } \\
\text { remain higher at all } \\
\text { CMB counts. } \\
\text { Although CMBs } \\
\text { should generally not } \\
\text { affect antithrombotic } \\
\text { decisions, in IS or } \\
\text { TIA patients with a } \\
\text { large number of } \\
\text { CMBs (e.g.>5) the } \\
\text { risks of future ICH } \\
\text { and IS are finely } \\
\text { balanced, } \\
\text { antithrombotics } \\
\text { might cause net } \\
\text { harm. Further studies } \\
\text { are needed in patients } \\
\text { on anticoagulants. }\end{array}$ & $\begin{array}{l}\text { CMBs presence and } \\
\text { increasing burden } \\
\text { increase the risk of } \\
\text { ICH. } \\
\text { Patients with lobar } \\
\text { ICH with a high } \\
\text { burden of strictly } \\
\text { lobar CMBs or other } \\
\text { haemorrhagic } \\
\text { markers (e.g. cortical } \\
\text { superficial siderosis), } \\
\text { should if possible } \\
\text { avoid } \\
\text { antithrombotics. } \\
\text { NOACs are preferable } \\
\text { to VKA. LAAO is an } \\
\text { option in ICH patients } \\
\text { with AF. }\end{array}$ \\
\hline
\end{tabular}

\section{Non-stroke (older community) populations}

The diagnostic accuracy of a strictly lobar CMB pattern for CAA seems limited in non-ICH (community) cohorts: in a recent study strictly lobar CMBs had a positive predictive value for pathology-proven CAA of only $25 \%$ (32), though participants had very few CMBs (33). 
Longitudinal studies of outcome related to CMBs in community cohorts are shown in Table 1. In the Rotterdam study (23) of 4759 participants aged $\geq 45$ years with mean follow-up of 4.9 years, CMBs were associated with an increased risk of all stroke (HR 1.93; 95\% CI 1.25 to 2.99); this was lower (and not statistically significant) for IS (HR 1.52; 95\% CI 0.91 to 2.53) than for ICH (HR 5.64; 95\% CI 1.66 to 19.53). Non-strictly lobar CMBs (i.e. non-CAA pattern), were associated with an increased the risk of both IS and ICH while strictly lobar CMBs (indicating probable CAA) were associated only with $\mathrm{ICH}$ risk. Six participants with multiple CMBs developed a first-ever ICH during follow-up; 3 had used antithrombotic agents (either platelet inhibitors or oral anticoagulants). However, the overall stroke risk associated with CMBs was not affected by the use of antithrombotics. Pre-existing CMBs were associated with lacunar infarction whilst incident lobar CMBs are associated with progression of white matter lesions, suggesting shared ischaemic mechanisms.

A large Japanese population-based study showed that CMB presence was associated with both IS (hazard ratio $4.48 ; 95 \%$ CI 2.20 to 12.2 ) and ICH (hazard ratio 50.2; $95 \%$ CI 16.7 to 150.9)(26), but did not explore CMB burden, topography, or associations with antithrombotics. A hospital-based study in patients with incidental lobar CMBs without stroke reported $\mathrm{ICH}$ rates comparable to CAA-associated ICH (31) and that warfarin was an independent risk factor for ICH $(\mathrm{p}=0.02)$. However, this population had a median of 10 lobar CMBs, suggesting severe CAA, so these findings cannot be generalised to other stroke-free populations with incidentally found CMBs.

In summary, in community-dwelling populations, there is no clear evidence that the benefits of IS prevention by the use of antithrombotic drugs outweigh the risk of ICH in people with CMBs. Further interventional controlled clinical trials, including stratification according to CMB presence, burden and distribution, will be needed to definitively answer this question. 


\section{Ischaemic stroke and TIA populations}

The clinical relevance of CMBs is perhaps most uncertain in the IS and TIA population, because standard care includes antithrombotics for stroke secondary prevention. Does any increased risk of $\mathrm{ICH}$ in patients with $\mathrm{CMBs}$ outweigh the benefit in reducted future IS risk associated with antithrombotic therapy? Although risk instruments can be used to assess overall future IS risk in $\mathrm{AF}$ (e.g. $\mathrm{CHA}_{2} \mathrm{DS}_{2} \mathrm{VASC}$ ) or after TIA (ABCD2), as well as overall bleeding risk in AF (e.g. HAS-BLED), there are currently very limited data on how CMBs and other brain imaging findings might help personalise antithrombotic therapy to maximise benefit and minimise risk.

In recent studies, antiplatelets $(34-36)$ and anticoagulants $(36,37)$ are associated with the presence of CMBs and the development of new CMBs over time. However, establishing the clinical relevance of $\mathrm{CMBs}$ requires key clinical outcomes, including recurrent stroke. A recent aggregate data meta-analysis from 15 studies of patients with IS or TIA including 5068 patients over a median of 18 months follow-up showed that baseline CMBs are associated with an increased risk of both IS (pooled RR 1.8; 95\% CI 1.4 to 2.5) and ICH (pooled RR $6.3 ; 95 \%$ CI 3.5 to 11.4 ) (27). The risk ratio for both IS and ICH increased with CMB burden, but more steeply for ICH than IS: in individuals with >5 CMBs the RR of IS was 2.7, while that of ICH was 14.1 (Figure 3). At all CMB counts, the absolute risk of IS exceeded that of $\mathrm{ICH}$, though in those with $>5 \mathrm{CMBs}$, the absolute risk of $\mathrm{ICH}(8.8 \%)$ approached that of IS (10.5\%). In randomised trials, antiplatelet agents only modestly reduce the absolute risk of ischemic stroke (0.5 to $2.5 \%$ ) (38), while the recent meta-analysis showed that $\geq 5 \mathrm{CMB}$ are associated with an absolute risk increase of $8.2 \%$ for ICH and $5.1 \%$ for IS. Since ICH is generally more severe than IS, it is possible that in individuals with $>5 \mathrm{CMBs}$, antithrombotic 
treatment may be associated with net harm. The prevalence of patients with $\geq 5 \mathrm{CMBs}$ ranged from 12 to $51 \%$, suggesting this dilemma will be encountered often in clinical practice. However, since most individuals in this meta-analysis were treated with antithrombotic drugs (79\% with antiplatelets, $15 \%$ with anticoagulants), it cannot be concluded that CMBs should be avoided in patients with $>5$ CMBs. The benefit of antithrombotics in IS/TIA patients with many (e.g. >5) CMBs will only be determined by randomised controlled trials. Nevertheless, these data do provide reassurance that in individuals with IS or TIA and $<5$ CMBs, there is no suggestion that antithrombotics are hazardous, so should be used according to current care guidelines.

Data on the association between CMBs and stroke risk on patients with IS or TIA treated with anticoagulants are extremely limited. A small study in 134 patients with TIA or IS associated with AF (65\% treated with anticoagulants) over a median follow-up of 2.4 years (39), found that CMBs were associated with an increased unadjusted risk of all stroke (21\% vs $9 \%, p=0.06$ ) but there was only $1 \mathrm{ICH}$. A study from Korea in 504 patients with IS or TIA (97\% discharged on anticoagulation) (29) found that strictly lobar CMBs were associated with ICH mortality (HR 5.91; 95\% CI 1.58 to 22.11) whilst increasing CMB burden was associated with all cause (HR 1.99; 95\% CI 1.03 to 3.85) and IS mortality (HR 3.39; $95 \%$ CI 1.39 to 8.28 ) but did not report on non-fatal IS or ICH. A retrospective study from the same Korean group including 550 ischaemic stroke patients with AF (83\% discharged on anticoagulation) found that higher CHADS2 and CHA(2)DS(2)VASC scores were associated with the presence and number of CMBs. Recurrent ICH was associated with CMB presence (HR 3.79; $95 \%$ CI 1.09 to 13.15 ) but not CHADS2 or CHA(2)DS(2)VASC scores; recurrent IS risk was not reported (40). A small prospective single centre study from Japan followed 119 patients with AF (86\% anticoagulated) for a median of 17 months (41); 
CMBs were not associated with recurrent stroke (both ICH and IS), but due to the small number of events IS and ICH risk could not be examined separately.

There is thus an urgent need for more large-scale data on how CMBs might affect the balance of IS and ICH in IS/TIA patients treated with oral anticoagulants. Two large large multicentre inception cohort studies will help to address this gap: Clinical Relevance of Microbleeds in

Stroke

(CROMIS

$2 ; \quad$ see

https://www.ucl.ac.uk/cromis-2,

https://clinicaltrials.gov/ct2/show/NCT02513316)(42) and Intracerebral Hemorrhage Due to Oral Anticoagulants: Prediction of the Risk by Magnetic Resonance (HERO; see http://heropub.pic.es, https://clinicaltrials.gov/ct2/show/NCT02238470).

\section{ICH populations}

The most feared, often lethal, complication of antithrombotic therapy is ICH. Recurrent ICH risk varies according to the location of the initial $\mathrm{ICH}$ : the annual $\mathrm{ICH}$ recurrence risk after deep (non-lobar, in the basal ganglia or brainstem) $\mathrm{ICH}$ is between 1.3 to $10.6 \%$ compared with 2.5 to $28.2 \%$ after lobar ICH. (43) While deep ICH is attributed to hypertensive arteriopathy, lobar ICH may be due to either hypertensive arteriopathy or CAA. Cohort studies in CAA-related ICH or CMBs, diagnosed according to the Boston criteria indicate a high recurrence rate of $\sim 10 \%$ per year (31). The presence, burden and distribution of CMBs might increase the risk of recurrent $\mathrm{ICH}$, and help to judge difficult antithrombotic decisions (Table 1). In a study of 207 survivors of ICH followed for a median of 20 months there were 39 recurrences of $\mathrm{ICH}(28)$. $\mathrm{CMB}$ number was associated with recurrent $\mathrm{ICH}$ in patients with lobar but not deep ICH, while antiplatelet use did not affect the risk of recurrent ICH in either lobar (HR $0.8 ; 95 \%$ CI 0.3 to $2.3, p=0.73$ ) or deep location (HR $1.2 ; 95 \%$ CI 0.1 to $14.3, p=$ 0.88). By contrast, a small single centre study in CAA-related $\mathrm{ICH}$ reported that aspirin was an independent risk factor for recurrent ICH (HR 3.95; 95\% CI 1.6 to $8.3, p=0.021$ ) (30). 
Three other studies found that increasing CMB burden is associated with increasing ICH risk $(5,6,30)$, but none reported on IS risk. Two of these studies included only patients with lobar ICH, whilst the third included both deep and lobar ICH. The risk of ICH was particularly high with >5CMBs (HR 4.12 95\% CI 1.6 to 9.3 vs. no CMBs $p=0.001$ (30) with a $51 \% 3$ year cumulative risk for $>5 \mathrm{CMBs}$ vs. $14 \% 3$ year cumulative risk for $1 \mathrm{CMB} \mathrm{p}=0.003(5)$.

The use of anticoagulants following ICH thus presents a major clinical dilemma. The risk of ischaemic stroke without antithrombotic treatment must be weighed carefully against the possible increase in $\mathrm{ICH}$ risk associated with antithrombotic therapy. A decision analysis which modelled warfarin for AF in an ICH survivor suggested that in lobar ICH avoiding warfarin increased quality-adjusted life (QOL) years by 1.9, compared with 0.3 for deep ICH; the authors concluded that anticoagulation for AF should not be offered to patients with lobar ICH and only to survivors of deep ICH if the risk of ischaemic events was high $(>7 \%$ per year)(44). However, CMBs were not considered in this analysis. By contrast, recent realworld studies in large datasets from ICH survivors with AF suggest that anticoagulation reduces mortality and ischaemic complications, without an increase in ICH $(45,46)$, and also reduced hospitalization costs (47). However, none of the real world studies stratified ICH by location, nor by CMB burden or distribution. Further studies in ICH cohorts phenotyped according to CAA diagnostic criteria, with assessment of interactions of CMB pattern and burden with antithrombotic use may help clarify this enduring clinical dilemma. Two ongoing randomised trials of antithrombotic use after ICH will also help guide clinicians in

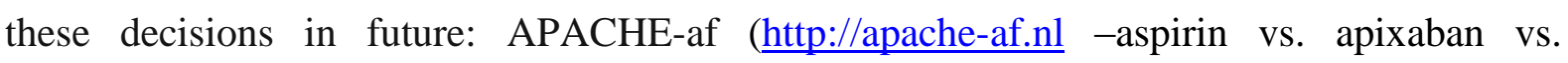
noantithrombotics for the treatment of AF in patients after ICH) and RESTART 
(www.restarttrial.org -antiplatlets vs, no antiplatelets in patients with ICH with an indication for antiplatelets).

\section{Other imaging markers}

Other imaging markers of small vessel disease include cortical superficial siderosis (cSS), leukoaraiosis and enlarged perivascular spaces. cSS seems to be strongly associated with probable CAA(48, 49) and with increased recurrent ICH risk(49-51), especially if disseminated (49).

\section{Conclusion}

Cerebral microbleeds are a risk factor for both future IS and ICH in all populations studied, including healthy older people people, and those with IS, TIA or ICH. Following IS or TIA treated with antithrombotics, increasing $\mathrm{CMB}$ burden increases the risk of $\mathrm{ICH}$ more steeply than that of IS; in patients with a large number of CMBs (e.g.>5) the risks of future ICH and IS are finely balanced, and antithrombotics might cause net harm. However, most of the evidence in IS and TIA cohorts is from patients treated with antiplatelet agents rather than anticoagulants. Large global collaborative networks will be needed to obtain the necessary data to assess any potential hazard of CMBs, especially associated with the use of in anticoagulants; the Microbleeds International Collaborative Network(52) will undertake a systematic review and individual patient data meta-analysis of the clinical relevance of CMBs in patients with TIA and ischaemic stroke treated with antithrombotics (the prospectively registered protocol published at: www.crd.york.ac.uk/PROSPERO/display_record.asp?ID=CRD42016036602). 
ICH patients with probable CAA (i.e. those with lobar ICH and either strictly lobar CMBs or disseminated cortical superficial siderosis) have a high baseline annual risk of ICH (>5\% per year), which is likely to be increased substantially with the use of anticoagulants. We suggest that these patients should usually avoid anticoagulation; if essential to prevent further ischaemic events (e.g. in the presence of high risk atrial fibrillation), non-vitamin K antagonists are preferable because of a lower risk of $\mathrm{ICH}(53)$. Alternatives to anticoagulation for patients with AF include left atrial appendage occlusion (54), which is as effective as oral anticoagulants but likely to have lower future ICH risk than long-term oral anticoagulation in ICH survivors. Figure 4 is a treatment algorithm suggested by the authors based on current evidence.

\section{Key points}

- $\mathrm{CMBs}$ can be due to both haemorrhagic and ischaemic mechanisms, and are associated with an increased risk of both IS and ICH in all populations studied, including community-dwelling older adults, IS or TIA, and ICH

- CMBs should not currently influence antithrombotic decisions in non-stroke (community-dwelling) populations

- In IS or TIA populations, a small number of CMBs $(<5)$ is associated with a higher risk of recurrent IS than $\mathrm{ICH}$, so should not routinely influence antithrombotic decisions

- In patients with IS or TIA treated with antithrombotics, an increasing burden (number) of CMBs is associated with a steep increase in ICH risk: individuals with a high $\mathrm{CMB}$ burden $(>5)$ have similar absolute risks of ICH and recurrent IS, so that antithrombotic use might cause net harm 
- $\mathrm{CMBs}$ and other haemorrhagic imaging markers (e.g. cortical superficial siderosis) are associated with a substantial risk of recurrent $\mathrm{CAA}$-related $\mathrm{ICH}$, and current limited evidence suggests that avoiding antithrombotics is probably appropriate in individuals with this high risk profile

\section{Acknowledgements}

Acknowledgements. The authors thank Dr Gargi Banerjee for help with Figure 2.

Financial support and sponsorship. Professor Werring and Dr Wilson both receive research support from the British Heart Foundation and The Stroke Association.

Conflicts of interest. Professor Werring has received speaking honoraria from Bayer and was UK Chief Investigator for a trial of ponezumab in cerebral amyloid angiopathy

\section{Important papers}

**Akoudad S, Portegies ML, Koudstaal PJ, Hofman A, van der Lugt A, Ikram MA, et al. Cerebral Microbleeds Are Associated With an Increased Risk of Stroke: The Rotterdam Study. Circulation. 2015;132(6):509-16.

Important paper which examines the associaiton of CMBs with both IS and ICH risk in a healthy population cohort. The paper explores both the distribution and burden of CMBs as well as their interaction with antithrombotics.

*Martinez-Ramirez S, Romero JR, Shoamanesh A, McKee AC, Van Etten E, PontesNeto $O$, et al. Diagnostic value of lobar microbleeds in individuals without intracerebral hemorrhage. Alzheimer's \& dementia : the journal of the Alzheimer's Association. 2015 
This radiological-pathology study examins the diagnostic value of CMBs between a hospital cohort and healthy patients in the community. They show lobar a strictly lobar CMB pattern has a low positive predictive value for CAA in community patients.

***ecurrent stroke risk and cerebral microbleed burden in ischemic stroke and TIA: A meta-analysis.Wilson D, Charidimou A, Ambler G, Fox ZV, Gregoire S, Rayson P, Imaizumi T, Fluri F, Naka H, Horstmann S, Veltkamp R, Rothwell PM, Kwa VI, Thijs V, Lee YS, Kim YD, Huang Y, Wong KS, Jäger HR, Werring DJ. Neurology. 2016. A large up-to-date meta-analysis comparing ICH and IS risk with regrard to CMB presence, burden and distribution in patients presenting with IS or TIA

*Kuramatsu JB, Gerner ST, Schellinger PD, Glahn J, Endres M, Sobesky J, et al. Anticoagulant reversal, blood pressure levels, and anticoagulant resumption in patients with anticoagulation-related intracerebral hemorrhage. JAMA : the journal of the American Medical Association. 2015;313(8):824-36.

*Nielsen PB, Larsen TB, Skjoth F, Gorst-Rasmussen A, Rasmussen LH, Lip GY. Restarting Anticoagulant Treatment After Intracranial Hemorrhage in Patients With Atrial Fibrillation and the Impact on Recurrent Stroke, Mortality, and Bleeding: A Nationwide Cohort Study. Circulation. 2015;132(6):517-25.

Both tof hese large observational registry studies show that restarting anticoagulation in patients with ICH and AF is associated with decreased mortlaity and ischaemic complications without an increase in $\mathrm{ICH}$.

**van Veluw SJ, Biessels GJ, Klijn CJ, Rozemuller AJ. Heterogeneous histopathology of cortical microbleeds in cerebral amyloid angiopathy. Neurology. 2016;86(9):867-71 Recent histopathological correlation study which reveals CMBs have a heterogeneous histopathological substrate suggesting multiple different mechanisms

*Janaway BM, Simpson JE, Hoggard N, Highley JR, Forster G, Drew D, et al. Brain haemosiderin in older people: pathological evidence for an ischaemic origin of MRI microbleeds. Neuropathology and applied neurobiology. 2013.

*Grutzendler J, Murikinati S, Hiner B, Ji L, Lam CK, Yoo T, et al. Angiophagy prevents early embolus washout but recanalizes microvessels through embolus extravasation. Science translational medicine. 2014;6(226):226ra31.

Both of the above papers give mechanistic insights into the possible ischaemic mechanisms which may lead the formation fo CMBs.

*Microbleeds International Collaborative Network. Worldwide collaboration in the Microbleeds International Collaborative Network. Lancet neurology. 2016 Volume 15, Issue 11, October 2016, Pages 1113-1114

A global collaborative effort which will help answer key questions about CMBs and stroke risk. Only large international efforts will have statistical power to address prediction of rare outcomes, including antithrombotic-related ICH. 



\section{References}

1. Offenbacher H, Fazekas F, Schmidt R, Koch M, Fazekas G, Kapeller P. MR of cerebral abnormalities concomitant with primary intracerebral hematomas. AJNR American journal of neuroradiology. 1996;17(3):573-8.

2. Fazekas F, Kleinert R, Roob G, Kleinert G, Kapeller P, Schmidt R, et al. Histopathologic analysis of foci of signal loss on gradient-echo $T 2^{*}$-weighted MR images in patients with spontaneous intracerebral hemorrhage: evidence of microangiopathy-related microbleeds. AJNR American journal of neuroradiology. 1999;20(4):637-42.

3. Knudsen KA, Rosand J, Karluk D, Greenberg SM. Clinical diagnosis of cerebral amyloid angiopathy: validation of the Boston criteria. Neurology. 2001;56(4):537-9.

4. Shoamanesh A, Kwok CS, Benavente O. Cerebral microbleeds: histopathological correlation of neuroimaging. Cerebrovascular diseases. 2011;32(6):528-34.

5. Greenberg SM, Eng JA, Ning M, Smith EE, Rosand J. Hemorrhage burden predicts recurrent intracerebral hemorrhage after lobar hemorrhage. Stroke; a journal of cerebral circulation. 2004;35(6):1415-20.

6. Jeon SB, Kang DW, Cho AH, Lee EM, Choi CG, Kwon SU, et al. Initial microbleeds at MR imaging can predict recurrent intracerebral hemorrhage. Journal of neurology. 2007;254(4):508-12.

7. Thijs V, Lemmens R, Schoofs C, Gorner A, Van Damme P, Schrooten M, et al. Microbleeds and the risk of recurrent stroke. Stroke; a journal of cerebral circulation. 2010;41(9):2005-9.

8. Lim JS, Hong KS, Kim GM, Bang OY, Bae HJ, Kwon HM, et al. Cerebral microbleeds and early recurrent stroke after transient ischemic attack: results from the korean transient ischemic attack expression registry. JAMA neurology. 2015;72(3):301-8.

9. Janaway BM, Simpson JE, Hoggard N, Highley JR, Forster G, Drew D, et al. Brain haemosiderin in older people: pathological evidence for an ischaemic origin of MRI microbleeds. Neuropathology and applied neurobiology. 2013.

10. Grutzendler J, Murikinati S, Hiner B, Ji L, Lam CK, Yoo T, et al. Angiophagy prevents early embolus washout but recanalizes microvessels through embolus extravasation. Science translational medicine. 2014;6(226):226ra31.

11. Tanskanen M, Makela M, Myllykangas L, Notkola IL, Polvikoski T, Sulkava R, et al. Prevalence and severity of cerebral amyloid angiopathy: a population-based study on very elderly Finns (Vantaa 85+). Neuropathology and applied neurobiology. 2012;38(4):329-36.

12. Diener HC, Selim MH, Molina CA, Greenberg SM. Embolic Stroke, Atrial Fibrillation, and Microbleeds: Is There a Role for Anticoagulation? Stroke; a journal of cerebral circulation. 2016;47(3):904-7.

13. Greenberg SM, Vernooij MW, Cordonnier C, Viswanathan A, Al-Shahi Salman R, Warach S, et al. Cerebral microbleeds: a guide to detection and interpretation. Lancet neurology. 2009;8(2):16574.

14. Stehling $C$, Wersching $H$, Kloska SP, Kirchhof $P$, Ring J, Nassenstein I, et al. Detection of asymptomatic cerebral microbleeds: a comparative study at 1.5 and 3.0 T. Academic radiology. 2008;15(7):895-900.

15. Gregoire SM, Werring DJ, Chaudhary UJ, Thornton JS, Brown MM, Yousry TA, et al. Choice of echo time on GRE T2*-weighted MRI influences the classification of brain microbleeds. Clinical radiology. 2010;65(5):391-4.

16. Cheng AL, Batool S, McCreary CR, Lauzon ML, Frayne R, Goyal M, et al. Susceptibilityweighted imaging is more reliable than $\mathrm{T} 2{ }^{*}$-weighted gradient-recalled echo MRI for detecting microbleeds. Stroke; a journal of cerebral circulation. 2013;44(10):2782-6.

17. Gregoire SM, Chaudhary UJ, Brown MM, Yousry TA, Kallis C, Jager HR, et al. The Microbleed Anatomical Rating Scale (MARS): reliability of a tool to map brain microbleeds. Neurology.

2009;73(21):1759-66. 
18. Cordonnier C, Potter GM, Jackson CA, Doubal F, Keir S, Sudlow CL, et al. improving interrater agreement about brain microbleeds: development of the Brain Observer MicroBleed Scale (BOMBS). Stroke; a journal of cerebral circulation. 2009;40(1):94-9.

19. Kuijf HJ, Brundel M, de Bresser J, van Veluw SJ, Heringa SM, Viergever MA, et al. SemiAutomated Detection of Cerebral Microbleeds on 3.0 T MR Images. PloS one. 2013;8(6):e66610.

20. van Veluw SJ, Biessels GJ, Klijn CJ, Rozemuller AJ. Heterogeneous histopathology of cortical microbleeds in cerebral amyloid angiopathy. Neurology. 2016;86(9):867-71.

21. Imaizumi T, Inamura S, Kohama I, Yoshifuji K, Nomura T, Komatsu K. Nascent deep microbleeds and stroke recurrences. Journal of stroke and cerebrovascular diseases : the official journal of National Stroke Association. 2014;23(3):520-8.

22. Martinez-Ramirez S, Romero JR, Shoamanesh A, McKee AC, Van Etten E, Pontes-Neto O, et al. Diagnostic value of lobar microbleeds in individuals without intracerebral hemorrhage. Alzheimer's \& dementia : the journal of the Alzheimer's Association. 2015;11(12):1480-8.

23. Akoudad S, Portegies ML, Koudstaal PJ, Hofman A, van der Lugt A, Ikram MA, et al. Cerebral Microbleeds Are Associated With an Increased Risk of Stroke: The Rotterdam Study. Circulation. 2015;132(6):509-16.

24. Gregoire SM, Brown MM, Kallis C, Jager HR, Yousry TA, Werring DJ. MRI detection of new microbleeds in patients with ischemic stroke: five-year cohort follow-up study. Stroke; a journal of cerebral circulation. 2010;41(1):184-6.

25. Pasquini M, Benedictus MR, Boulouis G, Rossi C, Dequatre-Ponchelle N, Cordonnier C. Incident Cerebral Microbleeds in a Cohort of Intracerebral Hemorrhage. Stroke; a journal of cerebral circulation. 2016;47(3):689-94.

26. Bokura H, Saika R, Yamaguchi T, Nagai A, Oguro H, Kobayashi S, et al. Microbleeds are associated with subsequent hemorrhagic and ischemic stroke in healthy elderly individuals. Stroke; a journal of cerebral circulation. 2011;42(7):1867-71.

27. Wilson D, Charidimou A, Ambler G, Fox ZV, Gregoire S, Rayson P, et al. Recurrent stroke risk and cerebral microbleed burden in ischemic stroke and TIA: A meta-analysis. Neurology.

2016;87(14):1501-10.

28. Viswanathan A, Rakich SM, Engel C, Snider R, Rosand J, Greenberg SM, et al. Antiplatelet use after intracerebral hemorrhage. Neurology. 2006;66(2):206-9.

29. Song TJ, Kim J, Song D, Nam HS, Kim YD, Lee HS, et al. Association of cerebral microbleeds with mortality in stroke patients having atrial fibrillation. Neurology. 2014;83(15):1308-15.

30. Biffi A, Halpin A, Towfighi A, Gilson A, Busl K, Rost N, et al. Aspirin and recurrent intracerebral hemorrhage in cerebral amyloid angiopathy. Neurology. 2010;75(8):693-8.

31. van Etten ES, Auriel E, Haley KE, Ayres AM, Vashkevich A, Schwab KM, et al. Incidence of symptomatic hemorrhage in patients with lobar microbleeds. Stroke; a journal of cerebral circulation. 2014;45(8):2280-5.

32. Martinez-Ramirez S, Romero JR, Shoamanesh A, McKee AC, Van Etten E, Pontes-Neto O, et al. Diagnostic value of lobar microbleeds in individuals without intracerebral hemorrhage.

Alzheimer's \& dementia : the journal of the Alzheimer's Association. 2015.

33. Wilson D, Werring DJ. Establishing the "meaning" of microbleeds: Clinical context or lobar microbleed burden? Alzheimer's \& dementia : the journal of the Alzheimer's Association. 2016;12(1):85-6.

34. Liu S, Li C. Antiplatelet Drug Use and Cerebral Microbleeds: A Meta-analysis of Published Studies. Journal of stroke and cerebrovascular diseases : the official journal of National Stroke Association. 2015;24(10):2236-44.

35. Wobith M, Mayer C, Belke M, Haag A, Gerstner A, Teepker M, et al. Predictors of New Cerebral Microbleeds in Patients with Antiplatelet Drug Therapy. Journal of stroke and cerebrovascular diseases : the official journal of National Stroke Association. 2016;25(7):1671-7. 
36. O'Donnell MJ, Eikelboom JW, Yusuf S, Diener HC, Hart RG, Smith EE, et al. Effect of apixaban on brain infarction and microbleeds: AVERROES-MRI assessment study. American heart journal. 2016;178:145-50.

37. Horstmann S, Mohlenbruch M, Wegele C, Rizos T, Laible M, Rauch G, et al. Prevalence of atrial fibrillation and association of previous antithrombotic treatment in patients with cerebral microbleeds. European journal of neurology : the official journal of the European Federation of Neurological Societies. 2015;22(10):1355-62.

38. Antithrombotic Trialists C. Collaborative meta-analysis of randomised trials of antiplatelet therapy for prevention of death, myocardial infarction, and stroke in high risk patients. Bmj. 2002;324(7329):71-86.

39. Haji S, Planchard R, Zubair A, Graff-Radford J, Rydberg C, Brown RD, Jr., et al. The clinical relevance of cerebral microbleeds in patients with cerebral ischemia and atrial fibrillation. Journal of neurology. 2016;263(2):238-44.

40. Song TJ, Kim J, Lee HS, Nam CM, Nam HS, Heo JH, et al. The frequency of cerebral microbleeds increases with CHADS(2) scores in stroke patients with non-valvular atrial fibrillation. European journal of neurology : the official journal of the European Federation of Neurological Societies. 2013;20(3):502-8.

41. Charidimou A, Inamura S, Nomura T, Kanno A, Kim SN, Imaizumi T. Cerebral microbleeds and white matter hyperintensities in cardioembolic stroke patients due to atrial fibrillation: single-centre longitudinal study. Journal of the neurological sciences. 2016;369:263-7.

42. Charidimou A, Wilson D, Shakeshaft C, Ambler G, White M, Cohen H, et al. The Clinical Relevance of Microbleeds in Stroke study (CROMIS-2): rationale, design, and methods. International journal of stroke : official journal of the International Stroke Society. 2015;10 Suppl A100:155-61.

43. Poon MT, Fonville AF, Al-Shahi Salman R. Long-term prognosis after intracerebral haemorrhage: systematic review and meta-analysis. Journal of neurology, neurosurgery, and psychiatry. 2013.

44. Eckman MH, Rosand J, Knudsen KA, Singer DE, Greenberg SM. Can patients be anticoagulated after intracerebral hemorrhage? A decision analysis. Stroke; a journal of cerebral circulation. 2003;34(7):1710-6.

45. Kuramatsu JB, Gerner ST, Schellinger PD, Glahn J, Endres M, Sobesky J, et al. Anticoagulant reversal, blood pressure levels, and anticoagulant resumption in patients with anticoagulationrelated intracerebral hemorrhage. JAMA : the journal of the American Medical Association. 2015;313(8):824-36.

46. Nielsen PB, Larsen TB, Skjoth F, Gorst-Rasmussen A, Rasmussen LH, Lip GY. Restarting Anticoagulant Treatment After Intracranial Hemorrhage in Patients With Atrial Fibrillation and the Impact on Recurrent Stroke, Mortality, and Bleeding: A Nationwide Cohort Study. Circulation. 2015;132(6):517-25.

47. Vestergaard AS, Skjoth F, Lip GY, Larsen TB. Effect of Anticoagulation on Hospitalization Costs After Intracranial Hemorrhage in Atrial Fibrillation: A Registry Study. Stroke; a journal of cerebral circulation. 2016;47(4):979-85.

48. Linn J, Halpin A, Demaerel P, Ruhland J, Giese AD, Dichgans M, et al. Prevalence of superficial siderosis in patients with cerebral amyloid angiopathy. Neurology. 2010;74(17):1346-50.

49. Charidimou A, Peeters AP, Jager R, Fox Z, Vandermeeren Y, Laloux P, et al. Cortical superficial siderosis and intracerebral hemorrhage risk in cerebral amyloid angiopathy. Neurology. 2013;81(19):1666-73.

50. Linn J, Wollenweber FA, Lummel N, Bochmann K, Pfefferkorn T, Gschwendtner A, et al. Superficial siderosis is a warning sign for future intracranial hemorrhage. Journal of neurology. 2013;260(1):176-81.

51. Koo HW, Jo KI, Yeon JY, Kim JS, Hong SC. Clinical features of high-degree centrum semiovaleperivascular spaces in cerebral amyloid angiopathy. Journal of the neurological sciences.

2016;367:89-94. 
52. Network MIC. Worldwide collaboration in the Microbleeds International Collaborative Network. Lancet neurology. 2016.

53. Ruff CT, Giugliano RP, Braunwald E, Hoffman EB, Deenadayalu N, Ezekowitz MD, et al. Comparison of the efficacy and safety of new oral anticoagulants with warfarin in patients with atrial fibrillation: a meta-analysis of randomised trials. Lancet. 2014;383(9921):955-62.

54. Horstmann S, Zugck C, Krumsdorf U, Rizos T, Rauch G, Geis N, et al. Left atrial appendage occlusion in atrial fibrillation after intracranial hemorrhage. Neurology. 2014;82(2):135-8. 


\section{Figure titles}

Figure 1: Distribution of microbleeds.

A. Mixed distribution of microbleeds in both deep (thalamic and basal ganglia) and lobar regions; this pattern is hypothesised to be due to either severe hypertensive arteriopathy, or mixed hypertensive arteriopathy and cerebral amyloid angiopathy

B. Strictly lobar distribution of microbleeds, suggesting a diagnosis of probable cerebral amyloid angiopathy (CAA)

Figure 2: Hypothetical possible mechanisms of CMBs and intracerebral haemorrhage.

Figure 3: Risk ratio of both ischaemic stroke and intracerebral haemorrhage depending on CMB burden in patients with ischaemic stroke or TIA

Legend: CMB -cerebral microbleeds; TIA-transient ischaemic attack; IS -ischaemic stroke; ICH intracerebral haemorrhage

Figure 4: Suggested decision making algorithm for antithrombotic use in patients with CMBs based upon the authors recommendations

Legend: TIA -transient ischaemic attack; ICH -intracerebral haemorrhage; CMB -cerebral microbleed; AF -atrial fibrillation; LAA - left atrial appendage; CAA -cerebral amyloid angiopathy; RESTART - REstart or STop Antithrombotics Randomised Trial; APACHE-AF - Apixaban versus Antiplatelet drugs or no antithrombotic drugs after anticoagulation-associated intraCerebral HaEmorrhage in patients with Atrial Fibrillation. 